\title{
GRIK3 rs490647 is a Common Genetic Variant between Personality and Subjective Well-being in Chinese Han Population
}

\author{
Lin An ${ }^{\mathrm{a}, \mathrm{c} \#}$, Chuanxin Liu ${ }^{\mathrm{b} \#}$, Naixin Zhang ${ }^{\mathrm{a}, \mathrm{c}}$, Zhixuan Chen ${ }^{\mathrm{a}, \mathrm{c}}$, Decheng Ren ${ }^{\mathrm{a}, \mathrm{c}}$, \\ Fan Yuan ${ }^{\text {a,c }}$, Ruixue Yuan ${ }^{\text {a,c }}$, Yan Bi ${ }^{\text {a,c }}$, Lei Ji ${ }^{\text {a,c }}$, Zhenming Guo ${ }^{\text {a,c }}$, Gaini Ma ${ }^{\text {a,c }}$,

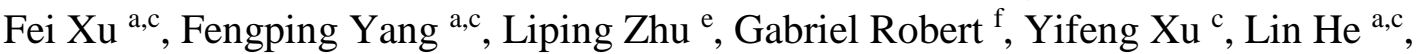 \\ Bo Bai ${ }^{d^{*}}$, Tao $\mathrm{Yu}^{\text {a,b,e** }}$, Guang $\mathrm{He}^{\mathrm{a}, \mathrm{c}^{*}}$ \\ ${ }^{a}$ Bio-X Institutes, Key Laboratory for the Genetics of Developmental and Neuropsychiatric Disorders, Shanghai Jiao Tong University, \\ 1954 Huashan Road, Shanghai 200030, China \\ ${ }^{b}$ School of Mental Health, Jining Medical University, 16 Hehua Rd, Taibaihu New District, Jining, Shandong 272067, China \\ ${ }^{c}$ Shanghai Key Laboratory of Psychotic Disorders, and Brain Science and Technology Research Center, Shanghai Jiao Tong University, \\ 1954 Huashan Road, Shanghai 200030, China \\ ${ }^{d}$ Institute of Neurobiology, Jining Medical University, 16 Hehua Rd, Taibaihu New District, Jining, Shandong 272067, China \\ e Shanghai Center for Women and Children's Health, 339 Luding Road, Shanghai 200062, China \\ ${ }^{f}$ Department of psychiatry, EA4712 Behavior and Basal Ganglia Unit, Medical University of Rennes, 1 Rennes, France
}

\begin{abstract}
Personality and subjective well-being (SWB) have been suggested to be strongly related in previous studies. This study was intended to confirm the relationship between personality and SWB and tried to seek out the genetic variants which underlie both personality and SWB. The subjects were 890 participants from Chinese Han population. We evaluated their personality using the Big Five Inventory (BFI) and used the Satisfaction With Life Scale (SWLS) to reflect their SWB. Five single nucleotide polymorphisms (SNPs) were selected from the literature (rs1426371, rs2164273, rs322931, rs3756290, rs490647) and genotyped for genetic association study. We found negative correlations between neuroticism and SWB. On the contrary, extraversion and agreeableness were positively associated with SWB. Three SNPs (rs2164273, rs3756290, rs490647) out of the five were found to connect with personality (extraversion, neuroticism, conscientiousness and openness to experience) and rs490647 variants of GRIK3 was also associated with SWB. Individuals carrying G allele at this site were predisposed to have lower risk to be neuroticism and greater chance to be extraverted, open and satisfied with their life. In summary, our study revealed that rs 490647 might be a good candidate genetic variant for personality and SWB in Chinese Han population.
\end{abstract}

\section{Keywords}

Personality;

Subjective Well-being;

Genetic Overlap;

GRIK3;

Chinese Han Population.

\section{Article History:}

Received: 06 February 2019

Accepted: 05 April 2019

\section{1- Introduction}

Personality traits are known to be associated with subjective well-being (SWB). Widely accepted, personality traits can be measured through the five-factor model (FFM), also known as "Big Five", including Extraversion (E), Neuroticism (N), Conscientiousness (C), Agreeableness (A), and Openness to Experience (O) [1, 2]. SWB is defined as the overall emotional and cognitive evaluation of people's lives, including happiness, fulfilment and life satisfaction [35]. Life satisfaction is most commonly used to measure one's SWB [4, 6] through the Satisfaction With Life Scale (SWLS) [7]. Many studies showed close relationships between personality traits and SWB. More precisely, extraversion

* CONTACT: Heguangbiox@163.com \# These authors contributed equally to this work.

DOI: http://dx.doi.org/10.28991/esj-2019-01171

(C) This is an open access article under the CC-BY license (https://creativecommons.org/licenses/by/4.0/). 
and neuroticism showed opposite pattern: extraversion has been repeatedly positively associated with life satisfaction while neuroticism was negatively correlated [8-10]. Furthermore, both the two dimensions acted as strong predictors for SWB, with the same opposite pattern $[11,12]$. However, the results on the other three dimensions (i.e. agreeableness, conscientiousness and openness to experience) were inconsistent. Although most studies were mainly based on western cohorts, similar conclusions have been achieved from Asian individuals. Studies carried out in Indian, Japan, South Korea and China have showed that neuroticism and extraversion were associated with life satisfaction [13-16].

Above and beyond the phenotypic associations between personality and SWB, their genetic components and overlap have been the focus of a substantial amount of research. A meta-analysis of twin studies found that about $40 \%$ of individual differences in personality were caused by genetic factors [17, 18]. Genome-wide association studies (GWAS) have probed several remarkable variants associated with personality [19-21], especially for extraversion and neuroticism [22-24]. SWB is also moderately heritable. Twin and family studies showed that genetic variations may typically account for $30 \%$ to $40 \%$ of the variance of SWB [10, 25-27]. Simultaneously, SNPs significantly associated with SWB were observed as well [23, 28-30]. While personality and SWB have been found to be correlated at a behavioural level and literature point to possible molecular mechanistic and genetic overlaps, only one study [10] demonstrated that SWB was associated with personality through common genes, but neither a certain gene nor specific molecular loci was presented.

The purpose of this study was to reveal the underlying genetic relations of personality and SWB. We selected five SNPs associated with personality traits or SWB based on the prior GWAS [22-24, 30].

\section{2- Materials and Methods}

\section{2-1- Subjects}

We recruited 890 unrelated Chinese Han college students (339 males and 551 females, age: $20.24 \pm 1.59$ ). All participants signed the informed consents and filled out the questionnaires measuring SWB and personality traits. The study protocol has been appraised and confirmed by the Ethics Committee of the Bio-X Institutes, Shanghai Jiao Tong University. The peripheral blood was collected for each student and the standard phenol-chloroform method was used in DNA extraction.

\section{2-2- SNP Selection and Genotyping}

The SNPs were selected according to the previous GWAS [22-24, 30]. These genetic variants were discovered to be associated with SWB or personality traits. The minor allele frequency (MAF) should be higher than 0.05 in East Asians. We included five SNPs (rs1426371, rs2164273, rs322931, rs3756290, rs490647). All SNPs are located in the intron region except for the downstream rs490647. More detailed information about the SNPs analysed is provided in Table 1.

Genotyping of all five SNPs applied the matrix-assisted laser desorption/ionization time of flight(MALDI-TOF) mass spectrometer on MassARRAY® Analyzer 4 platform (Sequenom, San Diego, CA). Assay Design Suite v2.0 from the Mysequenom online software was employed in probes and primers design.

Table 1. The five SNPs analysed in this study and the distribution of alleles and genotypes in 890 participants

\begin{tabular}{|c|c|c|c|c|c|c|c|c|c|c|}
\hline Gene & SNP ID ${ }^{a}$ & $\begin{array}{c}\text { Chromosome } \\
\text { position }^{b}\end{array}$ & Location & Allele $^{c}$ & $\begin{array}{c}\text { Allele } \\
\text { frequency }\end{array}$ & & $\begin{array}{l}\text { Genotype } \\
\text { frequency }\end{array}$ & & & $\begin{array}{c}\text { HWE } \\
p \text {-value }\end{array}$ \\
\hline WSCD2 & rs1426371 & $12: 108236003$ & Intron & $\mathrm{A} / \mathrm{G}$ & $\begin{array}{c}\mathrm{A} \\
1031(57.9)\end{array}$ & $\begin{array}{c}\mathrm{G} \\
749(42.1)\end{array}$ & $\begin{array}{c}\text { A/A } \\
296(33.3)\end{array}$ & $\begin{array}{c}\text { G/A } \\
439(49.3)\end{array}$ & $\begin{array}{c}\mathrm{G} / \mathrm{G} \\
155(17.4)\end{array}$ & 0.938 \\
\hline MTMR9 & rs2164273 & $8: 11310990$ & Intron & $\mathrm{A} / \mathrm{G}$ & $\begin{array}{c}\mathrm{A} \\
482(27.1)\end{array}$ & $\begin{array}{c}\mathrm{G} \\
1298(72.9)\end{array}$ & $\begin{array}{c}\text { G/G } \\
476(53.5)\end{array}$ & $\begin{array}{c}\mathrm{A} / \mathrm{G} \\
348(38.9)\end{array}$ & $\begin{array}{c}\text { A/A } \\
68(7.6)\end{array}$ & 0.897 \\
\hline LINC01221 & rs322931 & 1:199050726 & Intron & $\mathrm{C} / \mathrm{T}$ & $\begin{array}{c}\mathrm{C} \\
1467(82.4)\end{array}$ & $\begin{array}{c}\mathrm{T} \\
313(17.6)\end{array}$ & $\begin{array}{c}\mathrm{C} / \mathrm{C} \\
596(67.0)\end{array}$ & $\begin{array}{c}\mathrm{C} / \mathrm{T} \\
275(30.9)\end{array}$ & $\begin{array}{c}\mathrm{T} / \mathrm{T} \\
19(2.1)\end{array}$ & 0.143 \\
\hline RAPGEF6 & rs3756290 & $5: 131616057$ & Intron & $\mathrm{C} / \mathrm{T}$ & $\begin{array}{c}\mathrm{C} \\
1048(58.9)\end{array}$ & $\begin{array}{c}\mathrm{T} \\
732(41.1)\end{array}$ & $\begin{array}{c}\mathrm{C} / \mathrm{C} \\
316(35.5)\end{array}$ & $\begin{array}{c}\mathrm{T} / \mathrm{C} \\
416(46.7)\end{array}$ & $\begin{array}{c}\mathrm{T} / \mathrm{T} \\
158(17.8)\end{array}$ & 0.584 \\
\hline GRIK3 & rs490647 & $1: 36777142$ & Downstream & $\mathrm{A} / \mathrm{G}$ & $\begin{array}{c}\mathrm{A} \\
1064(59.8)\end{array}$ & $\begin{array}{c}\mathrm{G} \\
716(40.2)\end{array}$ & $\begin{array}{c}\mathrm{A} / \mathrm{A} \\
315(35.4)\end{array}$ & $\begin{array}{c}\text { G/A } \\
434(48.8)\end{array}$ & $\begin{array}{c}\mathrm{G} / \mathrm{G} \\
141(15.8)\end{array}$ & 0.916 \\
\hline
\end{tabular}

HWE: Hardy-Weinberg Equilibrium. $p$-value: Pearson's $p$ value, significant $p(<0.05)$ values are in bold.

a According to the dbSNP database.

b The SNP Chromosome positions are based on the NCBI human genome build GRCh38.

c The allele under the slash is the minor allele.

\section{2-3- Behavioural Measures}

The personality was measured using the Big Five Inventory (BFI) [31]. The BFI is a 44-item questionnaire measuring the personality on the Big Five dimensions including Extraversion, Neuroticism, Agreeableness, Conscientiousness and 
Openness to experience. The final scores on five factors for individuals are decided by $8-10$ items. Each item uses a Likert scale ranging from 1 (strongly disagree) to 5 (strongly agree).

The life satisfaction reflecting one's SWB was assessed by the Satisfaction With Life Scale (SWLS) [7], which contains 5 items in a 7-point response format ranging from 1(strongly disagree) to 7 (strongly agree).

\section{2-4- Statistical Analysis}

SHEsisPlus (http://shesisplus.bio-X.cn/SHEsis.html) was applied to analyse allelic and genotypic distributions and Hardy-Weinberg equilibrium [32]. We detected the association between the candidate SNPs with behavioural measures (i.e. personality and SWB) in five genetic models by "SNPassoc" R package (http://www.r-project.org/). Heat map illustrating correlations was also achieved on R software through "Corrplot" package. Hierarchical regression analysis was performed using SPSS ${ }^{\circledR}$ Statistics version 24.0. For all analysis, two tailed $p$ values were adapted and statistical significance was set for $p<0.05$. Research methodology is summarized in Figure 1.
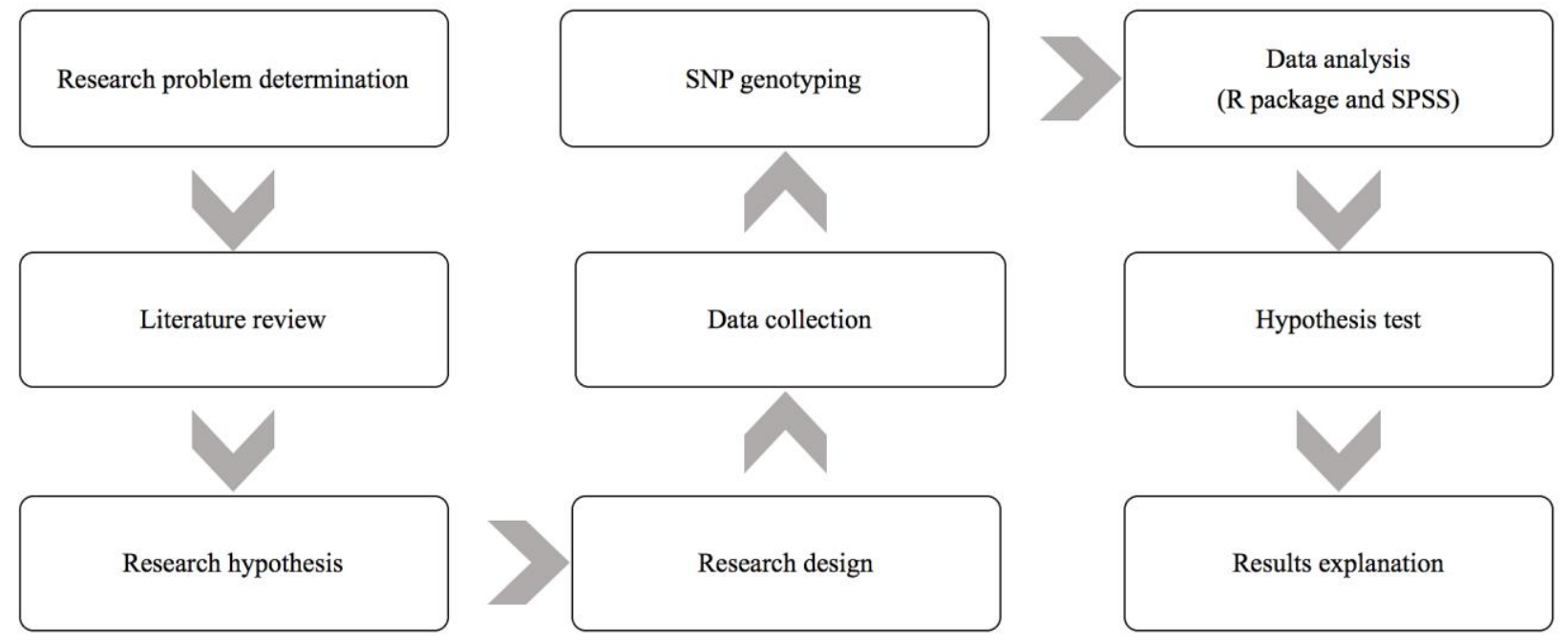

Figure 1. Research methodology flowchart

\section{3- Results}

\section{3-1- Phenotypic Correlations between Personality Traits and SWB}

Baseline characteristics of the 890 recruited students are shown in Table 2. Their mean scores on SWB and five dimensions of personality were described. And other factors we assumed to have impacts on SWB are also summarized in Table 2.

Heat map (Figure 2) shows the phenotypic correlation between five personality traits and SWB. Among the five personality traits, neuroticism was negatively correlated to SWB while extraversion, agreeableness, conscientiousness and openness to experience showed positive correlations. All five personality traits were significantly correlated with SWB. As expected, neuroticism showed the strongest and negative correlation with SWB $(r=-0.64, \mathrm{t}(888)=-24.9, p$ $<0.001)$ while extraversion was positively associated with SWB $(r=0.61, \mathrm{t}(888)=22.804, p<0.001)$. However, we found that agreeableness, conscientiousness and openness to experience were also positively correlated with SWB (agreeableness: $r=0.59, \mathrm{t}(888)=21.63, p<0.001$; conscientiousness: $r=0.49$, $\mathrm{t}(888)=16.679, p<0.001$; openness to experience: $r=0.47, \mathrm{t}(888)=15.728, p<0.001)$.

To test whether personality explained a significant amount of variance over the other demographic variables, we conducted hierarchical regression analysis (Table 3). In step 1, five personality traits were added as variables and they accounted for total 48.4\% variance in SWB. Extraversion $(\mathrm{t}(875)=2.749, p=0.006)$, neuroticism $(\mathrm{t}(875)=-6.586, p$ $<0.001)$ and agreeableness $(\mathrm{t}(875)=5.466, p<0.001)$ were considered significant predictors for SWB. In step 2 and step 3, demographic variables were added. Contrasting with personality traits, the added variance explained by sociodemographic variables was only $7.1 \%$, suggesting that personality is a greater contributor to SWB than sociodemographic. 
Table 2. Baseline characteristics of all 890 participants

\begin{tabular}{|c|c|c|}
\hline Variable & Mean & SD \\
\hline Age(years) & 20.24 & 1.59 \\
\hline $\mathrm{BMI}\left(\mathrm{kg} / \mathrm{m}^{2}\right)$ & 21.79 & 4.83 \\
\hline Subjective Well-being & 20.26 & 7.31 \\
\hline Extraversion & 26.09 & 6.75 \\
\hline Neuroticism & 23.52 & 6.21 \\
\hline Agreeableness & 34.95 & 5.59 \\
\hline Conscientiousness & 29.59 & 6.24 \\
\hline \multirow[t]{2}{*}{ Openness to experience } & 34.77 & 6.23 \\
\hline & $\mathbf{N}$ & $\%$ \\
\hline \multicolumn{3}{|l|}{ Gender } \\
\hline Male & 339 & 38.1 \\
\hline Female & 551 & 61.9 \\
\hline \multicolumn{3}{|l|}{ Sleep } \\
\hline Very bad & 14 & 1.6 \\
\hline $\mathrm{Bad}$ & 31 & 3.5 \\
\hline General & 367 & 41.2 \\
\hline Good & 324 & 36.4 \\
\hline Very good & 154 & 17.3 \\
\hline \multicolumn{3}{|l|}{ Exercise(h) } \\
\hline$<0.5$ & 284 & 31.9 \\
\hline $0.5-1.0$ & 398 & 44.7 \\
\hline $1.0-2.0$ & 150 & 16.9 \\
\hline$>2.0$ & 58 & 6.5 \\
\hline \multicolumn{3}{|l|}{ Family income } \\
\hline Lower than average & 197 & 22.1 \\
\hline Average & 639 & 71.8 \\
\hline Higher than average & 54 & 6.1 \\
\hline \multicolumn{3}{|c|}{ Average monthly expense (yuan) } \\
\hline$<500$ & 95 & 10.7 \\
\hline $500-1000$ & 426 & 47.9 \\
\hline $1000-1500$ & 228 & 25.6 \\
\hline $1500-2000$ & 74 & 8.3 \\
\hline$>2000$ & 67 & 7.5 \\
\hline \multicolumn{3}{|l|}{ Religious } \\
\hline Yes & 56 & 6.3 \\
\hline No & 834 & 93.7 \\
\hline \multicolumn{3}{|l|}{ Child } \\
\hline One child & 342 & 38.4 \\
\hline More than one child & 548 & 61.6 \\
\hline
\end{tabular}

SD: standard deviation; BMI: body mass index 


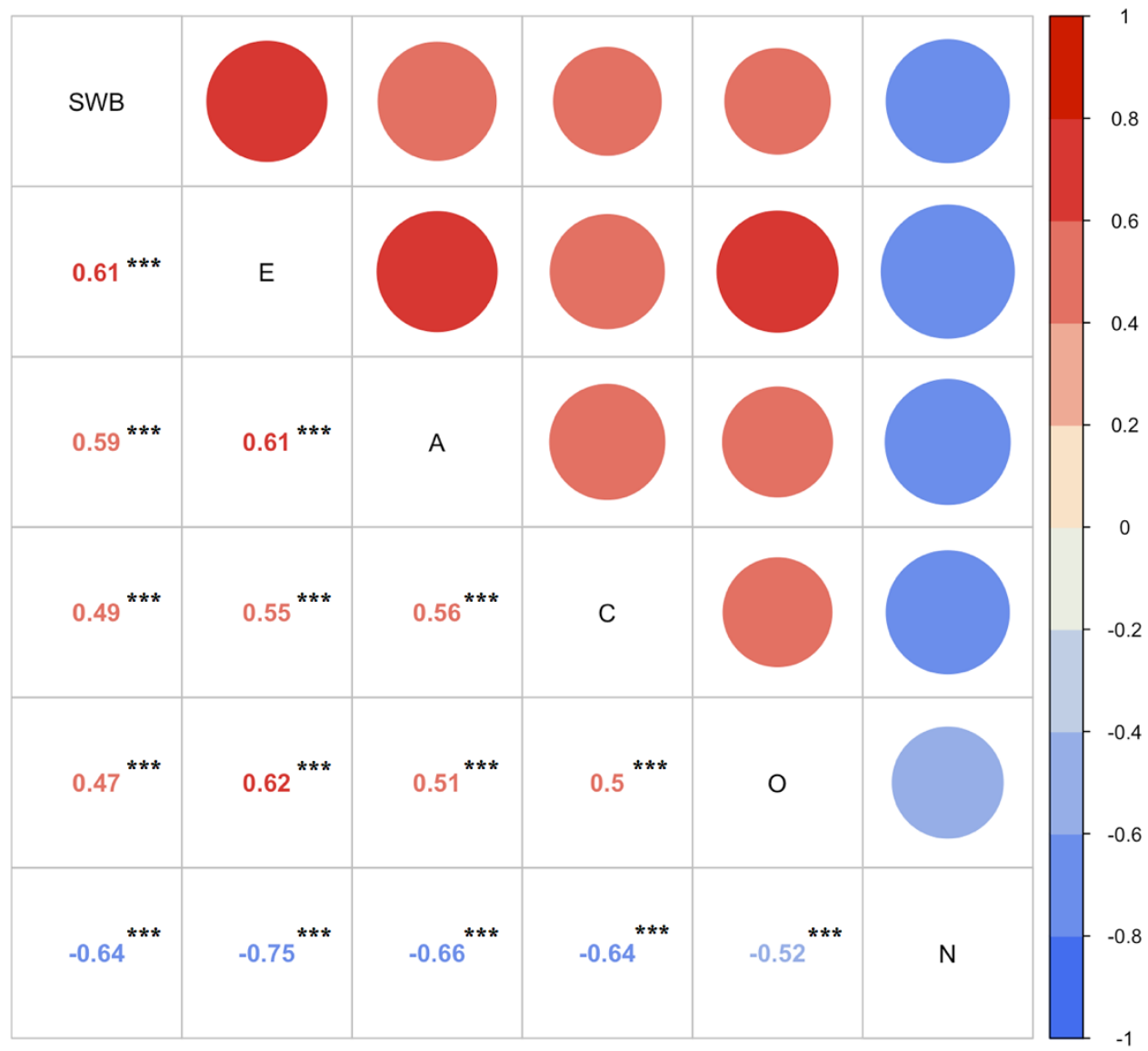

Figure 2. Heat map illustrating correlations between personality traits and subjective well-being

The values in the lower triangular matrix is correlation coefficients (Pearson's $r$ ). In the upper triangular matrix, big circles in dark colors indicates strong correlations. Positive correlations are showed in red while negative correlations are showed in blue. The asterisks show the significant levels.

E: Extraversion, A: Agreeableness, C: Conscientiousness, O: Openness to experience, N: Neuroticism. *** $p<0.001$ (two tailed).

Table 3. Hierarchical regression analysis for predicting subjective well-being

\begin{tabular}{lcccccc}
\hline Variable & B & SD & B & t & $p$-value & Total $\mathbf{R}^{2}\left(\Delta \mathbf{R}^{2}\right)$ \\
\hline Step1: Personality traits & & & & & & $0.484(0.484)$ \\
Extraversion & 0.205 & 0.044 & 0.190 & 2.749 & 0.006 & \\
Neuroticism & -0.347 & 0.049 & 0.294 & -6.586 & $<0.001$ & \\
Agreeableness & 0.293 & 0.045 & 0.224 & 5.466 & $<0.001$ & \\
Conscientiousness & 0.048 & 0.039 & 0.041 & 1.849 & 0.065 & \\
Openness to experience & 0.071 & 0.038 & 0.061 & 1.233 & 0.218 & \\
Step 2: Demographic control & & & & & & $0.487(0.003)$ \\
Gender & 1.364 & 0.371 & 0.091 & 3.678 & $<0.001$ & \\
Age & -0.027 & 0.105 & -0.006 & -0.260 & 0.795 & \\
Step3: Other control & & & & & & $0.555(0.068)$ \\
Sleep & 1.327 & 0.223 & 0.156 & 5.951 & $<0.001$ & \\
BMI & -0.028 & 0.035 & -0.018 & 2.370 & 0.018 & \\
Exercise & 0.516 & 0.218 & 0.061 & 3.099 & 0.002 & \\
Family income & 2.440 & 0.352 & 0.169 & -0.783 & 0.434 & \\
Average monthly expense & 0.521 & 0.168 & 0.074 & -1.141 & 0.254 & \\
Religious & -0.782 & 0.685 & -0.026 & -0.233 & 0.816 & \\
Child & -0.086 & 0.368 & -0.006 & 6.925 & $<0.001$ & \\
\hline B is & & & & & \\
\hline
\end{tabular}

$\mathrm{B}$ is unstandardized linear regression coefficients and $\mathrm{SD}$ is standard deviation for $\mathrm{B}$.

$B$ is standardized linear regression coefficients.

$p$-value: Person's $p$ value, two tailed. 


\section{3-2- Genetic Associations of Personality Traits and SWB}

All five SNPs tested were in Hardy-Weinberg equilibrium ( $p>0.05$, Table 1$)$. Their gene information and the distributions of allele and genotype frequencies are shown in Table 1. In terms of association study for personality, two SNPs showed individual differences in extraversion (rs3756290: $p=0.042$, B (95\%CI) $=-1.025(-2.364 \sim-0.046)$; rs490647: $p=0.042, \beta(95 \% \mathrm{CI})=0.963(0.037 \sim 1.889))$ (Table 4). The rs490647 was also significant with neuroticism $(p=0.011, \beta(95 \% \mathrm{CI})=-0.769(-1.360 \sim-0.179))$ and openness to experience $(p=0.006, \beta(95 \% \mathrm{CI})=1.557(0.441 \sim$ $2.674))$. Besides, rs2164273 was associated with conscientiousness $(p=0.045, \beta(95 \% \mathrm{CI})=-0.841(-1.661 \sim-0.021))$. The associations remained significant while controlling for gender and age. Furthermore, among the above three personality lead-SNPs, rs490647 variants showed significant individual differences in association with SWB as well ( $p$ $=0.003, B(95 \% \mathrm{CI})=1.05(0.35 \sim 1.75))$. We ran five genetic models to further explore this result $($ Table 5$)$. We found that the G/G genotype was correlated with higher score of SWB. This marker was survived after adjusting for gender and age and after Bonferroni correction for multiple testing (Bonferroni corrected $p=0.018$ ).

Table 4. Genetic variants significantly associated with personality traits

\begin{tabular}{|c|c|c|c|c|c|c|c|}
\hline SNP & Reference allele & B & $95 \% \mathrm{CI}$ & $p$-value & $\mathbf{B}^{\mathbf{a}}$ & $95 \% \mathrm{CI}^{\mathrm{a}}$ & $p$-value ${ }^{a}$ \\
\hline \multicolumn{8}{|c|}{ Extraversion } \\
\hline rs 3756290 & $\mathrm{~T}$ & -1.025 & $(-2.364,-0.046)$ & 0.042 & -1.238 & $(-2.400,-0.076)$ & 0.037 \\
\hline rs490647 & $\mathrm{G}$ & 0.963 & $(0.037,1.889)$ & 0.042 & 0.952 & $(0.019,1.885)$ & 0.046 \\
\hline \multicolumn{8}{|c|}{ Neuroticism } \\
\hline rs490647 & G & -0.769 & $(-1.360,-0.179)$ & 0.011 & -0.653 & $(-1.245,-0.061)$ & 0.031 \\
\hline \multicolumn{8}{|c|}{ Conscientiousness } \\
\hline rs 2164273 & A & -0.841 & $(-1.661,-0.021)$ & 0.045 & -0.852 & $(-1.671,-0.032)$ & 0.042 \\
\hline \multicolumn{8}{|c|}{ Openness to experience } \\
\hline rs490647 & G & 1.557 & $(0.441,2.674)$ & 0.006 & 1.539 & $(0.419,2.660)$ & 0.007 \\
\hline
\end{tabular}

$\beta$ is standardized linear regression coefficients for effective allele. $p$-value: Pearson's $p$ value; CI, confidence interval

a Adjusted for age, gender in statistical analysis

Table 5. Association between rs490647 and subjective well-being in five genotype models

\begin{tabular}{|c|c|c|c|c|c|c|c|}
\hline Genotype rs490647 & $\mathbf{N}$ & Mean & SE & B $(95 \% \mathrm{CI})$ & $p$-value & B $(95 \% \mathrm{CI})^{\mathrm{a}}$ & $p$-value ${ }^{a}$ \\
\hline \multicolumn{8}{|l|}{ Codominant } \\
\hline $\mathrm{A} / \mathrm{A}$ & 315 & 19.58 & 0.41 & 0.00 & \multirow[t]{3}{*}{0.011} & 0.00 & \multirow[t]{3}{*}{0.009} \\
\hline G/A & 434 & 20.24 & 0.35 & $0.66(-0.40,1.72)$ & & $0.68(-0.38,1.74)$ & \\
\hline $\mathrm{G} / \mathrm{G}$ & 141 & 21.81 & 0.60 & $2.22(0.78,3.67)$ & & $2.27(0.82,3.73)$ & \\
\hline \multicolumn{8}{|l|}{ Dominant } \\
\hline $\mathrm{A} / \mathrm{A}$ & 315 & 19.58 & 0.41 & 0.00 & \multirow[t]{2}{*}{0.042} & 0.00 & \multirow[t]{2}{*}{0.038} \\
\hline G/A-G/G & 575 & 20.63 & 0.31 & $1.04(0.04,2.05)$ & & $1.07(0.06,2.08)$ & \\
\hline \multicolumn{8}{|l|}{ Recessive } \\
\hline A/A-G/A & 749 & 19.97 & 0.27 & 0.00 & 0.006 & 0.00 & \multirow[t]{2}{*}{0.005} \\
\hline $\mathrm{G} / \mathrm{G}$ & 141 & 21.81 & 0.60 & $1.84(0.53,3.15)$ & & $1.87(0.56,3.19)$ & \\
\hline \multicolumn{8}{|l|}{ Overdominant } \\
\hline A/A-G/G & 456 & 20.27 & 0.34 & 0.00 & 0.955 & 0.00 & \multirow[t]{3}{*}{0.950} \\
\hline G/A & 434 & 20.24 & 0.35 & $-0.03(-0.99,0.93)$ & & $-0.03(-0.99,0.93)$ & \\
\hline \multicolumn{7}{|l|}{ log-Additive } & \\
\hline $0,1,2$ & & & & $1.02(0.33,1.72)$ & 0.004 & $1.05(0.35,1.75)$ & 0.003 \\
\hline
\end{tabular}

SE: standard error

a Adjusted for age, gender in statistical analysis

\section{4- Discussion}

In this work, we analysed both phenotypic and genotypic associations between personality and SWB among 890 college students within Chinese Han population. Strong phenotypic relations between personality traits and SWB have been shown, especially for neuroticism, extraversion and agreeableness. In addition, we tested for genetic associations considering five SNPs (rs1426371, rs2164273, rs322931, rs3756290, rs490647) extracted from the original GWAS [2224, 30]. Three SNPs (rs2164273, rs3756290, rs490647) were found to correlate with personality and our results point to 
rs490647 as a possible shared genetic site between personality and SWB.

In line with previous studies [8-10], we found neuroticism to be negatively and extraversion to be positively related to SWB. Besides, we revealed that agreeableness also exhibited strong relation with SWB, consistent with another study carried out in China [33]. Although moderate, the positive correlation between conscientiousness and openness to experience with SWB might help to target promising psychotherapic strategies to improve SWB.

To our knowledge, little previous research has been conducted to show the genetic variants of SWB, and only several GWAS have discovered significant SNPs for two personality dimensions. Here, we used a genetic association approach and we found that two SNPs (rs3756290, rs490647) are associated with extraversion. In accordance with previous findings, rs490647 showed a significant association for neuroticism [22]. Besides, we ascertained genetic variants rs2164273 associated with conscientiousness and rs490647 associated with openness to experience in Chinese Han population. Since the genetic correlations between personality and SWB have been revealed in previous meta-analysis studies [34, 35], we further conducted association studies of SWB. rs490647 variant was found to be also significantly associated with SWB besides the three dimensions of personality. Therefore, it indicated that the SWB and personality might have shared gene loci.

As mentioned above, our results revealed rs490647 as the overlap significant SNP site for SWB and personality. rs490647 is an adenosine (A) / guanine (G) nucleotide variation. Previously, a study based on 106000 individuals has proved the significant association between rs490647 and neuroticism $\left(p=3.8 \times 10^{-8}\right)$ [22]. In that study, the reference allele A had a positive linear correlation with neuroticism. We confirmed this finding in 890 college students from Chinese Han population. Allele $\mathrm{G}$ was considered as the reference allele wherein $\mathrm{G} / \mathrm{G}$ genotype proclaimed lower risk for neuroticism. Additionally, we also described that allele $\mathrm{G}$ had the positive correlation with extraversion, openness to experience and happiness. People with G/G genotype tended to have higher scores on extraversion, openness to experience and life satisfaction. Overall these findings indicated that $\mathrm{rs} 490647 \mathrm{might}$ be a protective genetic variant lowering the risk for neuroticism and psychiatric disorders.

rs490647 is located at Chr1:36777142, downstream region of GRIK3 gene. The human gene GRIK3 encodes the glutamate ionotropic kainate receptor subunit GluR7 [36], which is involved in the regulation of glutamatergic synaptic neurotransmission [37]. GRIK3 gene possess a higher expression in brain tissues in contrast to non-brain tissues [38], especially enriched in mossy fibers and CA3 pyramidal cells synapses in hippocampus [37]. GluR7 is an important subunit of presynaptic kainate receptors that have low sensitivity to glutamate, conduct synaptic plasticity and facilitate glutamate release [39]. Excessive activation of glutamate receptors can lead to excitotoxicity [40], and GRIK3 has been proposed to be an excitotoxicity causing candidate [36]. Multiple studies have provided strong evidence for a significant correlation between GRIK3 and psychiatric disorders, such as schizophrenia and major depressive disorder(MDD) [4143]. Associations have been reported between GRIK3 genetic variants and recurrent MDD [44] and several personality traits [45]. Hence, as for our results, we speculated that people with G/G genotype at rs490647 or linked variants may express GRIK3 in a relatively low level to decrease glutamate release, avoid excessive glutamate receptors activation and keep the normal neuronal ionic gradient. They are at lower risk for mental disorders, easier to feel satisfied with their life and own positive personality such as extraversion and openness to experience.

The limitations of our study naturally include two aspects. The first one is the relative small sample size. Besides, we selected SNPs according to the previous GWAS and five SNPs in our study were from different genes, causing the insufficient SNP coverage for each gene. Hence, larger size of samples should be included and complete SNP coverage for specific gene especially GRIK3 are desirable for further study.

\section{5- Conclusion}

In summary, our study confirmed both phenotypic and genotypic association between personality and SWB. Five personality traits were significantly correlated with SWB. Neuroticism showed the strongest negative correlation with SWB. The rest four personality aspects showed positive correlation. Genetic variant rs490647 in downstream of GRIK3 might be a shared genetic variant for personality and SWB in Chinese Han population. People with G/G genotype tended to be extraverted, open and satisfied with their life and had a lower tendency to develop neuroticism. Due to the pilot nature of our work, future research should further develop and replicate these initial findings in larger samples and different ethnic groups. Above all, this is an interdisciplinary study integrating psychology and life science, unearthing not only the surface but also the underlying genetic relations between personality and SWB. The effective loci and related gene was found to disclose why personality is correlated to SWB. Thus, our study has provided a deeper understanding than usual psychological researches.

\section{6- Funding and Acknowledgements}

We appreciate the contribution of the members participating in this study. This work was supported by the National Key Research and Development Program (2016YFC0906400, 2016YFC1307000, 2016YFC0905000), the National 
Nature Science Foundation of China (81421061, 81361120389), the Shanghai Key Laboratory of Psychotic Disorders (13dz2260500), the Shanghai Leading Academic Discipline Project (B205), Overseas students science and technology activities project merit funding, Woman and Children's Health (No.15GWZK0401), and the Fundamental Research Funds for the Central Universities (16JXRZ01).

\section{7- Conflict of Interest}

The authors declare no conflict of interest.

\section{8- Ethical Approval}

All procedures performed in studies involving human participants were in accordance with the ethical standards of the institutional and/or national research committee and with the 1964 Helsinki declaration and its later amendments or comparable ethical standards.

\section{9- References}

[1] McCrae, Robert R., and Oliver P. John. "An Introduction to the Five-Factor Model and Its Applications." Journal of Personality 60, no. 2 (June 1992): 175-215. doi:10.1111/j.1467-6494.1992.tb00970.x.

[2] Goldberg, Lewis R. “An Alternative 'Description of Personality': The Big-Five Factor Structure.” Journal of Personality and Social Psychology 59, no. 6 (1990): 1216-1229. doi:10.1037/0022-3514.59.6.1216.

[3] Diener, Ed, Shigehiro Oishi, and Richard E. Lucas. "Personality, Culture, and Subjective Well-Being: Emotional and Cognitive Evaluations of Life." Annual Review of Psychology 54, no. 1 (February 2003): 403-425. doi:10.1146/annurev.psych.54. 101601.145056 .

[4] Diener, Ed, Eunkook M. Suh, Richard E. Lucas, and Heidi L. Smith. "Subjective Well-Being: Three Decades of Progress." Psychological Bulletin 125, no. 2 (1999): 276-302. doi:10.1037/0033-2909.125.2.276.

[5] Bartels, Meike, and Dorret I. Boomsma. "Born to Be Happy? The Etiology of Subjective Well-Being.” Behavior Genetics 39, no. 6 (September 3, 2009): 605-615. doi:10.1007/s10519-009-9294-8.

[6] Rietveld, C. A., D. Cesarini, D. J. Benjamin, P. D. Koellinger, J.-E. De Neve, H. Tiemeier, M. Johannesson, et al. "Molecular Genetics and Subjective Well-Being." Proceedings of the National Academy of Sciences 110, no. 24 (May 24, 2013): $9692-9697$. doi:10.1073/pnas.1222171110.

[7] Diener, Ed, Robert A. Emmons, Randy J. Larsen, and Sharon Griffin. “The Satisfaction With Life Scale.” Journal of Personality Assessment 49, no. 1 (February 1985): 71-75. doi:10.1207/s15327752jpa4901_13.

[8] Costa, Paul T., and Robert R. McCrae. "Influence of Extraversion and Neuroticism on Subjective Well-Being: Happy and Unhappy People.” Journal of Personality and Social Psychology 38, no. 4 (1980): 668-678. doi:10.1037/0022-3514.38.4.668.

[9] E., Richard, and Ed Diener. "Personality and Subjective Well-Being." The Science of Well-Being (2009): 75-102. doi:10.1007/978-90-481-2350-6_4.

[10] Weiss, Alexander, Timothy C. Bates, and Michelle Luciano. "Happiness Is a Personal(ity) Thing." Psychological Science 19, no. 3 (March 2008): 205-210. doi:10.1111/j.1467-9280.2008.02068.x.

[11] Schimmack, Ulrich, Phanikiran Radhakrishnan, Shigehiro Oishi, Vivian Dzokoto, and Stephan Ahadi. "Culture, Personality, and Subjective Well-Being: Integrating Process Models of Life Satisfaction.” Journal of Personality and Social Psychology 82, no. 4 (2002): 582-593. doi:10.1037/0022-3514.82.4.582.

[12] Schimmack, Ulrich, Ed Diener, and Shigehiro Oishi. "Life-Satisfaction Is a Momentary Judgment and a Stable Personality Characteristic: The Use of Chronically Accessible and Stable Sources.” Journal of Personality 70, no. 3 (June 2002): 345-384. doi:10.1111/1467-6494.05008.

[13] Tanksale, Deepa. "Big Five Personality Traits: Are They Really Important for the Subjective Well-Being of Indians?" International Journal of Psychology 50, no. 1 (March 27, 2014): 64-69. doi:10.1002/ijop.12060.

[14] Otonari, Jun, Jun Nagano, Makiko Morita, Sanjeev Budhathoki, Naotaka Tashiro, Kengo Toyomura, Suminori Kono, Kazue Imai, Keizo Ohnaka, and Ryoichi Takayanagi. "Neuroticism and Extraversion Personality Traits, Health Behaviours, and Subjective Well-Being: The Fukuoka Study (Japan)." Quality of Life Research 21, no. 10 (December 29, 2011): 1847-1855. doi:10.1007/s11136-011-0098-y.

[15] Ha, Shang E., and Seokho Kim. "Personality and Subjective Well-Being: Evidence from South Korea." Social Indicators Research 111, no. 1 (February 18, 2012): 341-359. doi:10.1007/s11205-012-0009-9.

[16] Zhai, Qingguo, Mike Willis, Bob O’Shea, Yubo Zhai, and Yuwen Yang. "Big Five Personality Traits, Job Satisfaction and Subjective Wellbeing in China." International Journal of Psychology 48, no. 6 (December 2013): 1099-1108. doi:10.1080/00207594.2012.732700. 
[17] Vukasović, Tena, and Denis Bratko. "Heritability of Personality: A Meta-Analysis of Behavior Genetic Studies.” Psychological Bulletin 141, no. 4 (2015): 769-785. doi:10.1037/bul0000017.

[18] Bouchard, Thomas J. "Genes, environment, and personality." Science-AAAS-Weekly Paper Edition 264, no. 5166 (1994): 17001701.

[19] Kim, Han-Na, Seung-Ju Roh, Yeon Ah Sung, Hye Won Chung, Jong-Young Lee, Juhee Cho, Hocheol Shin, and Hyung-Lae Kim. "Erratum: Genome-Wide Association Study of the Five-Factor Model of Personality in Young Korean Women." Journal of Human Genetics 60, no. 8 (August 2015): 463-463. doi:10.1038/jhg.2015.67.

[20] De Moor, Marleen H. M., Stéphanie M. van den Berg, Karin J. H. Verweij, Robert F. Krueger, Michelle Luciano, Alejandro Arias Vasquez, Lindsay K. Matteson, et al. "Meta-Analysis of Genome-Wide Association Studies for Neuroticism, and the Polygenic Association With Major Depressive Disorder.” JAMA Psychiatry 72, no. 7 (July 1, 2015 ): 642. doi:10.1001/jamapsychiatry.2015.0554.

[21] De Moor, M H M, P T Costa, A Terracciano, R F Krueger, E J C de Geus, T Toshiko, B W J H Penninx, et al. "Meta-Analysis of Genome-Wide Association Studies for Personality." Molecular Psychiatry 17, no. 3 (December 21, 2010): 337-349. doi:10.1038/mp.2010.128.

[22] Smith, D J, V Escott-Price, G Davies, M E S Bailey, L Colodro-Conde, J Ward, A Vedernikov, et al. "Erratum: Genome-Wide Analysis of over 106000 Individuals Identifies 9 Neuroticism-Associated Loci." Molecular Psychiatry 21, no. 11 (September 13, 2016): 1644-1644. doi:10.1038/mp.2016.177.

[23] Okbay, Aysu, Bart M L Baselmans, Jan-Emmanuel De Neve, Patrick Turley, Michel G Nivard, Mark Alan Fontana, et al. "Genetic Variants Associated with Subjective Well-Being, Depressive Symptoms and Neuroticism Identified through GenomeWide Analyses.” Nature Genetics 48, no. 6 (April 18, 2016): 624-633. doi:10.1038/ng.3552.

[24] Lo, Min-Tzu, David A Hinds, Joyce Y Tung, Carol Franz, Chun-Chieh Fan, Yunpeng Wang, Olav B Smeland, et al. "GenomeWide Analyses for Personality Traits Identify Six Genomic Loci and Show Correlations with Psychiatric Disorders." Nature Genetics 49, no. 1 (December 5, 2016): 152-156. doi:10.1038/ng.3736.

[25] D.T. Lykken, T.J. Bouchard, Jr., M. McGue, A. Tellegen. “The Minnesota Twin Family Registry: some initial findings.” Acta Genet Med Gemellol (Roma) 39, no.1 1990): 35-70.

[26] NES, R. B., E. Røysamb, K. Tambs, J. R. Harris, and T. Reichborn-Kjennerud. "Subjective Well-Being: Genetic and Environmental Contributions to Stability and Change." Psychological Medicine 36, no. 07 (March 30, 2006 ): 1033. doi:10.1017/s0033291706007409.

[27] Stubbe, J. H., D. Posthuma, D. I. Boomsma, and E. J. C. De Geus. "Heritability of Life Satisfaction in Adults: a Twin-Family Study.” Psychological Medicine 35, no. 11 (June 29, 2005): 1581. doi:10.1017/s0033291705005374.

[28] Feldman, Ruth, Mikhail Monakhov, Maayan Pratt, and Richard P. Ebstein. "Oxytocin Pathway Genes: Evolutionary Ancient System Impacting on Human Affiliation, Sociality, and Psychopathology.” Biological Psychiatry 79, no. 3 (February 2016): 174-184. doi:10.1016/j.biopsych.2015.08.008.

[29] Jia, Tianye, Christine Macare, Sylvane Desrivières, Dante A. Gonzalez, Chenyang Tao, Xiaoxi Ji, Barbara Ruggeri, et al. "Neural Basis of Reward Anticipation and Its Genetic Determinants." Proceedings of the National Academy of Sciences 113, no. 14 (March 21, 2016): 3879-3884. doi:10.1073/pnas.1503252113.

[30] Wingo, A P, L M Almli, J S Stevens, T Jovanovic, T S Wingo, G Tharp, Y Li, et al. "Genome-Wide Association Study of Positive Emotion Identifies a Genetic Variant and a Role for microRNAs.” Molecular Psychiatry 22, no. 5 (September 6, 2016): 774-783. doi:10.1038/mp.2016.143.

[31] John, Oliver P., and Sanjay Srivastava. "The Big Five trait taxonomy: History, measurement, and theoretical perspectives." Handbook of personality: Theory and research 2, no. 1999 (1999): 102-138.

[32] Shen, Jiawei, Zhiqiang Li, Jianhua Chen, Zhijian Song, Zhaowei Zhou, and Yongyong Shi. "SHEsisPlus, a Toolset for Genetic Studies on Polyploid Species.” Scientific Reports 6, no. 1 (April 6, 2016). doi:10.1038/srep24095.

[33] Zhang, Liwei. "Prediction of Chinese Life Satisfaction: Contribution of Collective Self - esteem." International Journal of Psychology 40, no. 3 (June 2005): 189 - 200. doi:10.1080/00207590444000285.

[34] Weiss, Alexander, Bart M. L. Baselmans, Edith Hofer, Jingyun Yang, Aysu Okbay, Penelope A. Lind, Mike B. Miller, et al. "Personality Polygenes, Positive Affect, and Life Satisfaction." Twin Research and Human Genetics 19, no. 05 (August 22 , 2016): 407-417. doi:10.1017/thg.2016.65.

[35] DeNeve, Kristina M., and Harris Cooper. "The Happy Personality: A Meta-Analysis of 137 Personality Traits and Subjective Well-Being.” Psychological Bulletin 124, no. 2 (1998): 197-229. doi:10.1037/0033-2909.124.2.197. 
[36] Schiffer, Hans H., Geoffrey T. Swanson, Elizier Masliah, and Stephen F. Heinemann. "Unequal Expression of Allelic Kainate Receptor GluR7 mRNAs in Human Brains." The Journal of Neuroscience 20, no. 24 (December 15, 2000): 9025-9033. doi:10.1523/jneurosci.20-24-09025.2000.

[37] Bortolotto, Zuner A., Vernon R. J. Clarke, Caroline M. Delany, Michael C. Parry, Ilse Smolders, Michel Vignes, Ken H. Ho, et al. "Kainate Receptors Are Involved in Synaptic Plasticity." Nature 402, no. 6759 (November 1999): $297-301$. doi: $10.1038 / 46290$.

[38] Ohi, Kazutaka, Takamitsu Shimada, Toshiki Yasuyama, Kohei Kimura, Takashi Uehara, and Yasuhiro Kawasaki. "Spatial and Temporal Expression Patterns of Genes Around Nine Neuroticism-Associated Loci.” Progress in Neuro-Psychopharmacology and Biological Psychiatry 77 (July 2017): 164-171. doi:10.1016/j.pnpbp.2017.04.019.

[39] Pinheiro, P. S., D. Perrais, F. Coussen, J. Barhanin, B. Bettler, J. R. Mann, J. O. Malva, S. F. Heinemann, and C. Mulle. “GluR7 Is an Essential Subunit of Presynaptic Kainate Autoreceptors at Hippocampal Mossy Fiber Synapses." Proceedings of the National Academy of Sciences 104, no. 29 (July 9, 2007): 12181-12186. doi:10.1073/pnas.0608891104.

[40] Epstein, Franklin H., Stuart A. Lipton, and Paul A. Rosenberg. "Excitatory Amino Acids as a Final Common Pathway for Neurologic Disorders." New England Journal of Medicine 330, no. 9 (March 3, 1994): 613-622. doi:10.1056/nejm199403033300907.

[41] DeLisi, Lynn E., Andrea Mesen, Carlos Rodriguez, Arturo Bertheau, Beatrice LaPrade, Michelle Llach, Silvina Riondet, et al. "Genome-Wide Scan for Linkage to Schizophrenia in a Spanish-Origin Cohort from Costa Rica." American Journal of Medical Genetics 114, no. 5 (June 11, 2002): 497-508. doi:10.1002/ajmg.10538.

[42] Begni, S, M Popoli, S Moraschi, S Bignotti, G B Tura, and M Gennarelli. "Association Between the Ionotropic Glutamate Receptor Kainate 3 (GRIK3) Ser310ala Polymorphism and Schizophrenia.” Molecular Psychiatry 7, no. 4 (April 2002): 416418. doi:10.1038/sj.mp.4000987.

[43] Gray, A L, T M Hyde, A Deep-Soboslay, J E Kleinman, and M S Sodhi. "Sex Differences in Glutamate Receptor Gene Expression in Major Depression and Suicide." Molecular Psychiatry 20, no. 9 (July 14, 2015): 1057-1068. doi:10.1038/mp.2015.91.

[44] Schiffer, H.H., and S.F. Heinemann. "Association of the Human Kainate receptorGluR7 Gene (GRIK3) with Recurrent Major Depressive Disorder.” American Journal of Medical Genetics Part B: Neuropsychiatric Genetics 144B, no. 1 (2006): 20-26. doi:10.1002/ajmg.b.30374.

[45] Minelli, Alessandra, Catia Scassellati, Cristian Bonvicini, Jorge Perez, and Massimo Gennarelli. "An Association of GRIK3 Ser310Ala Functional Polymorphism with Personality Traits.” Neuropsychobiology 59, no. 1 (2009): $28-33$. doi:10.1159/000202827. 